\title{
Gene-edited plants cross European event horizon
}

\section{By lumping gene-edited plants together with other genetically modified organisms (GMOs), Europe's highest court has consigned this plant-breeding approach to a regulatory black hole.}

Shockwaves have continued to reverberate following the decision of $\checkmark$ the Court of Justice of the European Union (CJEU) to place geneedited plants within the remit of European rules for regulating GMOs. The CJEU ignored the Advocate General's recommendation to exempt gene-edited crops from oversight and instead chose to take a much more literal interpretation of the relevant law (see p. 799). As a result, the regulatory bar for gene-edited crops containing precise mutations is now higher than it is for radiation- and chemical-blitzed plants that contain thousands of random mutations. The question now is whether European lawmakers will act to correct their nonsensical rules.

Back in the 1980s, the European Union (EU) decided to regulate the process of making GMOs, as well as regulating the products themselves. This was the first indication that European regulations were beginning to gather mass. Directive 90/220/EEC was passed in 1990; another two directives were passed over the next 10 years (together with six commission decisions); and 2001 saw the release of directive 2001/18/EC, which became the text of reference. Eleven more amendments have been passed subsequently, each one propelling GMOs into an increasingly massive anomaly of paper work. Now the latest CJEU decision threatens to suck gene-edited plants completely over the regulatory event horizon.

EU regulation for GMOs was borne out of political expediency. In the 1980s, risks were anticipated and caution was warranted: companies built facilities downwind of Californian cities to ensure recombinant DNA blew out to sea; researchers wore hazmat suits when spraying ice-minus engineered bacteria on strawberries. But as the years passed and anticipated risks failed to materialize, rule makers elsewhere in the world rolled back their regulation. Not so EU legislators. They remained obdurately risk averse.

It matters not to European politicians that genetically modified food is nonhazardous to health. Nor that the glacial pace (time slows in black holes) and exorbitant costs of European regulations have extinguished what was at one time a burgeoning regional plant biotech sector. Nor that there any evidence of adverse events associated with adventitious levels of 'foreign' DNA in plants or food.

What does matter is that the CJEU decision has brought EU oversight to a final singularity of nonsense: the only genetic modifications that now escape European regulators' gaze are those induced by 'conventional' mutagenesis using ionizing radiation or DNA-damaging chemicals. So, according to EU law, generating thousands of random mutations is safe; but one designer change is cause to set the regulatory alarm bells ringing.

The practical question for EU regulators is how they can regulate an invisible process in a process-triggered system. Because if they can't, how can Europe stop exporting nations from sending 'illegal' crop products across its borders, and how can it stop conventional seed breeders from supplementing 'harmless' random mutagenesis with something decidedly more directed?
Going by European regulators' previous penchant for wrapping up GMOs in red tape, the most likely course of action would seem to be their tried-and-tested 'two-step' approach: step 1, insist on labeling to engage the consumer and shift the burden of proof to producers; step 2, enforce source verification across the entire production chain.

By analogy, then, conventional breeders will only be able to skirt the borders of the European regulatory black hole if they can show that their products have never been within pollinating distance of a gene-editing company or a gene-editing kit. Either that, or regulators will have to reel in the CRISPR tool suppliers so they know who is using the technique and where-an impossibility, given the ubiquity of gene-editing reagents. Finally, the European framework must prevent any smuggled or black-market gene-editing activity from entering its borders.

That the present situation is untenable and that European legislation is unfit for purpose is clear for all to see. So what are European politicians to do?

Alas, ridicule from the research community (p. 800) is unlikely to spur them to action. Twenty years after the last GMO crop was approved, Europe can still feed itself. Few go hungry. And few lament that Europe is now a genetically modified food-free zone (albeit a genetically modified feed-dependent one). The agricultural subsidies that maintain political intransigence serve as economic glue cementing the trading bloc. Furthermore, few in Europe's corridors of power have grasped the link between meteorological extremes and the need for rapidly adaptable, genetically modified crops. The only new wrinkle that might influence political opinion is that the biggest GMO producer is no longer American: in June, Bayer finalized its acquisition of Monsanto. In this respect, excluding GMO crops is no longer a means for politicians to stymie a marauding invader. It is now a pettifogging impediment to a European innovator and powerful agricultural giant, which last year spent a whopping $\$ 8,550,000$ on lobbying.

Thus, unless European legislators want their GMO rules to be held up to international ridicule, they have some stark choices to make. Either implement an unworkable regulatory framework that seeks to regulate gene-edited crops that are indistinguishable from unregulated conventional crops (e.g., using the two-rule system above). Or expand EU rules to regulate any product of plant breeding under directive 2001/18/EC (just capture everything and be damned). Or reverse the CJEU decision and remove gene-edited crops from oversight under the mutagenesis exemption (as originally suggested by the Advocate General). Or, finally, just let gene-edited crops enter the territory undetected (turn a blind eye).

Europe's burdensome GMO regulations have already ceded the advantage in bioengineered crops to the United States. Applying the same precautionary rules to gene-edited crops would be a monumental mistake. If European lawmakers let these crops fall into the same black hole as GMOs, they will likely be irretrievably lost from the European universe. 